\title{
Cuba's Strategy for Alzheimer Disease and Dementia Syndromes
}

\author{
Rodolfo I. Bosch-Bayard MD MS, Juan J. Llibre-Rodríguez MD MPH PhD DrSc, Alberto Fernández-Seco MD MS, \\ Carmen Borrego-Calzadilla MD MS, Mayra R. Carrasco-García MD MS, Tania Zayas-Llerena MS, \\ Carmen R. Moreno-Carbonell MD MS, Ana G. Reymond-Vasconcelos MD MS
}

\begin{abstract}
Dementia is a great challenge to public health in Cuba due to its impact on society and families. Cuba's National Intervention Strategy for Alzheimer Disease and Dementia Syndromes is designed to address this challenge. The Strategy includes working guidelines for primary and secondary care, education about rights of people with cognitive impairment, professional development, research, and health promotion and dementia prevention. An associated action plan, focused on primary care, includes proposals for creation of memory clinics, day centers and comprehensive rehabilitation services for cognitive stimulation. Short-term measures proposed include increasing early detection; creating a dementia morbidity and mortality registry; promoting professional training; providing support for families; and promoting basic and clinical research on dementia. Medium-term proposals aim to reduce dementia incidence and mortality by controlling risk factors and promoting healthy lifestyles, offering new treatment options and optimizing early detection. A set of indicators has been developed to evaluate strategy implementation. With this strategy, Cuba joins the small number of developing countries that have responded to WHO's call to improve care for patients with dementia and alleviate its impact on society and families.
\end{abstract}

KEYWORDS Dementia, Alzheimer disease, aging, national health programs, social stigma, primary prevention, health promotion, civil rights, Cuba

\section{INTRODUCTION}

Population aging in the countries of Latin America and the Caribbean presents new challenges, bringing with it an explosion of chronic non-communicable diseases, including dementia. Dementia's impact on society, families and health services is enormous - it is the leading cause of disability and demand for long-term care.[1-3] Its global costs have been estimated at US\$ 8.18 billion annually, a sum that exceeds $1 \%$ of global gross domestic product.[4] Its impact in Cuba is also substantial, with overall prevalence of $1.1 \%$, or 130,000 people.[5] Among adults aged $\geq 65$ years, dementia prevalence is estimated at $6.4 \%-10.8 \%,[6]$ and the age-standardized annual incidence rate is $2.2 \%$.[7] Dementia is Cuba's leading cause of disability.[3,8]

WHO produced a guide to nonspecialist health care interventions for neurological and mental disorders in 2010, and in 2012 called on governments to make dementia a health priority. Shortly thereafter, WHO produced its Mental Health Action Plan 2013-2020 to bridge the mental health service gap by focusing on expansion of specialized services in low-income contexts. $[9,10]$

In 2015, the First Ministerial Conference on Global Action against Dementia was held in Geneva. WHO Director General Dr Margaret Chan called upon member states to design and implement plans for dementia care, calling it the health priority that receives the least attention.[11] More than two dozen countries have developed national strategies and action plans for dementia.[12]
PAHO has developed a strategy and action plan for dementia and other debilitating disorders suffered primarily by older adults. Its aim is to promote universal access to health and health care coverage with interventions contributing to recovery or maintenance of functioning in people with, or at risk of, dementia and related disabilities.[13] Cuba, Costa Rica and Mexico were among the first middle- and low-income countries to develop national plans for dementia care.[14]

The starting point for developing a strategy to address the dementia problem is Cuba's health system, which is based on the principles of universal coverage and access, free medical and dental services, and comprehensive and regionalized care.

Health care is organized in three levels: primary, secondary and tertiary. The first level includes family doctor-and-nurse offices (CMF) and polyclinics (multidisciplinary health centers to which CMFs report, and which provide specialized services such as pediatrics, gynecology, psychiatry, internal medicine, psychology and rehabilitation).[15] All health promotion and disease prevention programs are delivered at this level, with community participation. Comprehensive rehabilitation services are also part of primary care, as are municipal mental health departments and day centers. Services for older adults is a priority at this level. The secondary level of care is provided in hospitals. The tertiary level involves institutes and research centers. All levels and institutions are closely linked (Figure 1).

Cuba's Strategy for Alzheimer and Dementia Syndromes starts with primary care, within a framework of clinical practice, scientific research, and actions undertaken with families and $\mathrm{Cu}$ ban society as a whole. The Strategy aims to enhance the training of medical personnel who treat patients with cognitive impairment, support patients' families and facilitate interaction among related social sectors. It is expected that its implementation will reduce hospitalizations, prepare caregivers to deal with such conditions, and help overcome stigma associated with dementia.

Figure 1: Levels of health care for patients with cognitive impairment

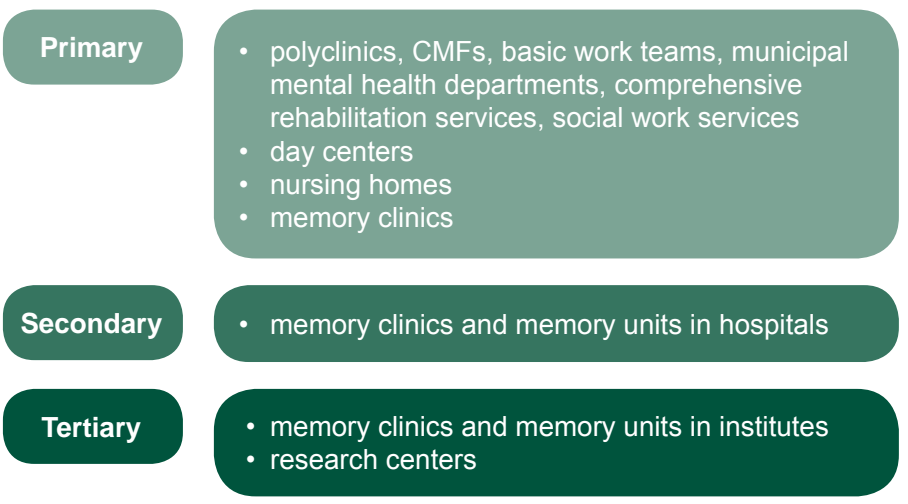

CMF: family doctor-and-nurse office 
The Strategy and associated action plan have the following objectives:[16]

- imrpove care for dementia patients and their families

- prevent cognitive impairment and dementia

- detect cognitive impairment early

- reduce stigma around dementia

- increase professional development

- train families in patient care

- promote basic, clinical and epidemiological research on dementia

- familiarize health teams with laws protecting the rights of older adults and people with cognitive impairment

Strategy design Leading the strategy formulation process were the Department of Older Adults, Social Assistance and Mental Health in the Ministry of Public Health (MINSAP) and Department of Primary Care (also in MINSAP), in coordination with the Alzheimer chapter of the Cuban Neuroscience Society. A group of 41 experts participated, made up of professors, researchers and specialists in dementia. Eleven participants had doctorates in medical sciences; the remainder held master's degrees. Most had more than 25 years' experience working on dementia. The consultation process employed the Delphi method,[17] and consisted of two workshops and two rounds of email consultations. The proposed strategy documents employed in the consultation were endorsed by the National School of Public Health. The first workshop took place in 2013, with support from MINSAP and PAHO. A followup workshop took place in 2014, also sponsored by MINSAP and PAHO, in collaboration with the Alzheimer chapter of the Cuban Neuroscience Society.

Strategy components The Strategy was drafted in 2013, published online in 2015 and formally approved for implementation in 2016. It consists of working guidelines, an action plan and a set of evaluation indicators. Each guideline specifies its objectives, contributions to the public health system, and proposed new actions. Special attention was given to the primary care level, since that is where most dementia treatment takes place.

In Cuba, care for older adults with dementia is delivered within the Comprehensive Older Adult Health Program,[18] but the primary and secondary care levels lack treatment protocols and sufficient interdisciplinary clinics. The Strategy addresses the issue with a focus on primary care, defines the respective roles of the various actors, proposes creation of specialized comprehensive dementia care units, introduces day care for people with cognitive impairment, proposes increased professional training and research in dementia, and promotes defense of the human rights of people suffering from mental impairment.

\section{Guidelines}

Primary care. This level includes polyclinics, municipal mental health departments, day centers for people with cognitive impairment, and comprehensive rehabilitation services. Family doctors and nurses are responsible for identifying patients with memory or behavioral problems; detecting at-risk patients through control of chronic, non-communicable diseases; and consulting specialists in internal medicine, psychiatry, psychology and geriatrics.

The Strategy proposes creation of memory clinics in every municipality, to provide multidisciplinary care for people with memory complaints, signs of cognitive impairment, or dementia. These units include a physician (geriatrician, neurologist, internist or family physician), a psychologist, and a social worker. Once a pa- tient has been assessed, consultations with additional specialists and referrals to comprehensive rehabilitation services or mental health departments may be required.

Objectives: Achieve early detection and interdisciplinary treatment of dementia.

Contributions to health system: Establish actions for care of cognitively impaired patients to be undertaken by family physicians, family nurses, internists, geriatricians, psychologists, mental health departments, community rehabilitation services, day centers and nursing homes.

Actions: Detect cognitive impairment early through periodic checkups of older adults in health clinics and home visits by family physicians, with referrals to a memory clinic if necessary.

Mental health departments have specialists in psychiatry, psychology, social work, nursing and occupational therapy, who take care of patients with psychological and behavioral symptoms, as well as their caregivers. These departments provide patients with cognitive stimulation, develop family education programs and organize "caregivers' schools" for those who work with older adults with cognitive problems.

New day centers for people with cognitive impairment provide care by nurses, nurses' aides and social workers for patients with mild or moderate dementia and without behavioral disorders. The Strategy aims to have such centers operating in all municipalities. At these centers, cognitive stimulation is incorporated into activities (music therapy, dance, handicrafts, group therapy and physical rehabilitation) aimed at preserving autonomy and functional ability to carry out activities of daily living. The centers also provide prevention and treatment of diseases associated with dementia, health education, and guidance for family caregivers to reduce caregiver burden and compensate for the consequences of having to leave paid employment in order to provide care.

Nursing homes: Due to increased numbers of older adults living alone, the number of beds for people with dementia and other disabilities in such homes has increased. This population is the most vulnerable and the most difficult to manage in the community. There has also been an increase in availability of day care places in these institutions for dementia patients (personal communication, Dr Alberto Fernández Seco, MINSAP).

Comprehensive rehabilitation services aim to restore and maintain older adults' physical, intellectual and psychological functioning and to improve their ability to carry out activities of daily living.[19] These services use treatments that employ cognitive stimulation for patients with cognitive impairment.

Secondary care. This level comprises hospitals that offer clinical and surgical services. Currently, not all hospitals have geriatric services.

Objective: Detect cognitive impairment in hospitalized older adults.

Contributions to health system: Introduce memory clinics into hospitals; actively detect cognitive impairment in hospitalized older adults; define criteria for referral for evaluation of cognitive impairment by other medical specialties. 
Actions: Increase skills and performance by health professionals treating people with cognitive impairment.

Education on rights of people with cognitive impairment. Health professionals need information on ethical and legal aspects of dementia not covered in their training.

Objectives: Health professionals should become familiar with the facets of civil and family law that protect older adults.

Contributions to health system: Highlight the vulnerabilities inherent in living with dementia and how these may make patients more apt to become victims of violence.

Actions: Familiarize health professionals with facets of civil and family law that protect older adults, and include these topics in curricula, in accordance with the need for enhanced professional training resulting from the growing number of people with cognitive impairment.

Professional development. Include dementia-related issues in undergraduate and postgraduate education in medicine, nursing and psychology.

Objective: Build skills and improve the performance of professionals involved in early detection and treatment of cognitive impairment and dementia.

Contributions to health system: Offer professional training programs on topics associated with dementia to increase quality of medical care for patients with cognitive impairment.

Actions: Propose necessary adjustments to medical, nursing, psychology and family medicine curricula to facilitate comprehensive assessment of older adult patients, including detection and treatment of dementias. Offers courses, diploma programs and master's degrees in dementia. Develop academic outreach activities such as the Alzheimer Section of the Medical University of Havana and the "A Healthy Mind in a Healthy Body" Research Section of the Medical University of Matanzas, which link students to research projects and community-level interventions being conducted by the university's Alzheimer studies department.

Research. Cuba has one of the most rapidly aging populations in Latin America. In 2020, the proportion of the population aged $>60$ years will reach $25 \%$. Should no cure be found for dementia, the number of people affected could reach 300,000 or $2.7 \%$ of the total population by 2040.[5] For this reason, dementia research must become a priority.

Objective: Develop areas of research into dementia as a health problem.

Contributions to health system: Identify dementia as a research priority.

Actions: Create national and international research projects on dementia; promote exchanges among institutions conducting basic and clinical research; conduct research on incidence, prevalence, risk factors, and diagnosis and treatment of dementia; increase the number of cost and health technology studies related to dementia.
Health promotion and dementia prevention. Many people believe that dementia cannot be prevented. It has been suggested that a $10 \%-25 \%$ reduction in risk factors like diabetes mellitus, hypertension, obesity, sedentarism, tobacco use and mid-life depression could bring Alzheimer prevalence down by 1.1-3 million cases worldwide;[20] delay clinical manifestations of the disease; and reduce dependence.[21-23]

In Cuba, physical activity by older adults is promoted at the primary care level, which is also responsible for implementation of national protocols for prevention and control of high blood pressure, tobacco use, cerebrovascular disease and diabetes. Action protocols for treatment of these conditions are also in place nationwide at the secondary level. Cuba is implementing the use of stroke rooms to improve treatment and recovery of people suffering from cerebrovascular disease. The Strategy calls for ongoing development of these programs, to help slow increased dementia incidence.

Objective: Develop health promotion and education actions to prevent dementia.

Contributions to health system: Propose dementia prevention as a key measure for its control.

Actions: Designate the National Health Promotion Center as coordinator of public education to encourage healthy lifestyles, including physical activity and mental activity (particularly among people aged $>60$ years), as well as to raise dementia awareness among caregivers and the general population; and reduce dementia risk factors.

Action plan This plan contains short- and medium-term measures to deal with dementia.

Short term

1. Increase early detection and reporting of dementia morbidity and mortality

2. Organize professional development activities on dementia detection and management in primary care

3. Adopt new measures to support families, including schools for caregivers, creation of support services, specialized day centers for people with cognitive impairment, as well as home support

4. Strengthen the Comprehensive Older Adult Health Program

5. Promote basic and clinical research on dementia.

6. Implement memory clinics

7. Employ cognitive stimulation in primary care for dementia patients

Medium term

1. Increase risk factor control and promote healthy lifestyles to reduce dementia incidence

2. Increase control of comorbid conditions and complications that contribute to mortality of dementia patients

3. Provide new treatment options

4. Optimize early detection through application of clinical skills, accompanied (when pertinent) by diagnostic tools such as neuroimaging, neurophysiology and biomarkers

Indicators Table 1 displays the indicators proposed to measure the Strategy's effectiveness. Structural indicators cover 
facilities and contexts that provide services to older adults. Process indicators are used to monitor action implementation. Outcome indicators are measures of policies' impact on the well-being of people with cognitive impairment. The indicators are a vehicle for proposing new actions and should be measured annually.

Strategy introduction Three factors motivated the Strategy's implementation as part of the Comprehensive Older Adult Health
Program: Cuba's accelerated demographic transition, changes in population health, and transformations in its public health system. The Strategy's contents have been publicized in the media, and efforts are under way to train personnel, create memory clinics and day centers, and conduct basic and clinical research. In some parts of Cuba, sociocultural projects with community participation are under way to promote successful aging and prevent dementia. Implementation is not homogeneous across Cuba, and the Strategy still needs to be rolled out in the central and eastern provinces. One constraint to its introduction is that it was approved without additional budget allocation, which may limit the extent to which some proposed actions can be executed.

Primary care

- existence of municipal memory clinic

- existence of a memory clinic in every polyclinic

- easy access to memory clinics and removal of architectural barriers in health centers

- existence of schools for caregivers in each health area served by a polyclinic

Structure - existence of senior centers for patients with mental incapacity in every municipality

- existence of residential facilities for dementia patients who need care in nursing homes

Secondary care

- existence of a hospital-based memory clinic

- creation and training of a health team for the memory clinic

- easy access to memory clinics and removal of architectural barriers to them

Research and teaching

- existence of programs in polyclinics and at the municipal level to train primary care personnel, caregivers and families

- number of caregivers trained

Process - at least one area of research related to aging and dementia (at primary and secondary levels of care)

- existence of social support networks for patients

- intersectoral participation in caregiving for older adults with dementia or cognitive impairment (with the support of social organizations, government, culture, food services, etc.)

\begin{tabular}{l|l} 
& - dementia incidence rate \\
Outcomes & dementia prevalence rate \\
- dementia mortality rate & one-year hospitalization rate from complications \\
- unintentional injury rate \\
- percent patient satisfaction with services provided
\end{tabular}

\section{CONCLUSIONS}

Caring for people with cognitive impairment requires broad social participation and protection of the rights of older adults. By implementing the Strategy for Alzheimer and Dementia Syndromes, Cuba joins the small number of developing countries that have responded to $\mathrm{WHO}$ recommendations to improve quality of care for patients with dementia and confront the impacts of this condition on society and families.

\section{ACKNOWLEDGMENTS}

The authors thank the experts who collaborated to this process and the people and institutions who made the workshops possible. $-1 / 2$

\section{REFERENCES}

1. Prince M, Bryce R, Albanese E, Wimo A, Ribeiro W, Ferri CP. The global prevalence of dementia: a systematic review and meta-analysis. Alzheimers Dement [Internet]. 2013 Jan [cited 2016 Jul 25];9(1):63-75. Available from: http://linkinghub .elsevier.com/retrieve/pii/S1552-5260(12)02531-9

2. Sousa RM, Ferri CP, Acosta D, Guerra M, Huang $\mathrm{Y}$, Jacob K, et al. The contribution of chronic diseases to the prevalence of dependence among older people in Latin America, China and India: A 10/66 Dementia Research Group population-based survey. BMC Geriatr [Internet]. 2010 Aug 6 [cited 2016 Jul 25];10:53. Available from: http://www.ncbi.nlm.nih.gov/pmc/articles/ PMC2923155/

3. Llibre JJ, Valhuerdi A, Calvo M, García RM, Guerra M, Laucerique $T$, et al. Dementia and other chronic diseases in older adults in Havana and Matanzas: The 10/66 Study in Cuba. MEDICC Rev [Internet]. 2011 Oct [cited 2016 Jan 7];13(4):30-7. Available from: http://www. medicc.org/mediccreview/index .php?issue $=18 \&$ id $=223 \& a=$ vahtml

4. Alzheimer's Disease International [Internet]. London: Alzheimer's Disease International; c2016. World Alzheimer Report 2010. The Global Economic Impact of Dementia; 2010 [cited 2013
Jan 21]. Available from: https://www.alz.co.uk/ research/world-report-2010

5. Llibre JJ. Demencias y enfermedad de Alzheimer en la población cubana. Havana: Editorial Científico Técnica; 2008. p. 36. Spanish.

6. Llibre-Rodríguez J, Valhuerdi A, Sánchez II, Reyna C, Guerra MA, Copeland JRM, et al. The prevalence correlates and impact of dementia in Cuba: a 10/66 group population-based survey. Neuroepidemiology [Internet]. 2008 Nov [cited 2016 Jan 7];31(4):243-51. Available from: http://www.ncbi.nlm.nih.gov/pmc/articles/ PMC2855229/

7. Prince M, Acosta D, Ferri CP, Guerra M, Huang Y, Llibre-Rodríguez JJ, et al. Dementia incidence and mortality in middle-income countries, and associations with indicators of cognitive reserve: a 10/66 Dementia Research Group populationbased cohort study. Lancet [Internet]. $2012 \mathrm{Jul}$ 7 [cited 2016 Mar 4];380(9836):50-8. Available from: http://www.sciencedirect.com/science/ article/pii/S0140673612603997/pdfft?md5=971 c120a81fde46a0c601d7b39b3470c\&pid=1-s2.0 -S0140673612603997-main.pdf

8. National Health Statistics and Medical Records Division (CU). Anuario Estadístico de la Salud 2015 [Internet]. Havana: Ministry of Public Health
(CU); 2016 [cited 2016 May 29]. p. 39. Available from: http://files.sld.cu/dne/files/2016/04/Anuario _2015_electronico-1.pdf. Spanish.

9. World Health Organization [Internet]. Geneva: World Health Organization; c2016. Guía de intervención mhGAP para los trastornos mentales, neurológicos y por uso de sustancias en el nivel de atención de la salud no especializada; 2011 [cited 2016 Feb 3]. 83 p. Available from: http://apps.who.int/iris/handle/10665/44498. Spanish.

10. World Health Organization. Plan de acción integral sobre salud mental 2013-2020. 66 ${ }^{\text {a }}$ Asamblea Mundial de la Salud [Internet]. Geneva: World Health Organization; 2013 May 27 [cited 2015 Sep 16]. Available from: http://apps.who.int/ iris/bitstream/10665/151028/1/A66_R8-sp.pdf. Spanish.

11. Dementia: turning fine aspirations into measurable progress. Lancet [Internet]. 2015 Mar 28 [cited 2015 Sep 16];385(9974):1151. Available from: http://www.thelancet.com/journals/lancet/ article/PIIS0140-6736(15)60618-3/fulltext

12. alz.org [Internet]. Chicago: Alzheimer's Association Advocacy Center; c2016. Global Efforts; [cited 2016 Jun 21]. Available from: http://www .alz.org/advocacy/global-efforts.asp\# 
13. World Health Organization; Pan American Health Organization. Estrategia y plan de acción sobre demencias en las personas mayores [Internet]. 2015 Sep 29 [cited 2016 Jan 18]. Available from: http://www.paho.org/hq/index.php?option=com _docman\&task=docdownload\&gid=31495\&ltem $\overline{i d}=270$ \&lang=es. Spanish.

14. Alzheimer Disease International [Internet]. London: Alzheimer Disease International; c2016. Global Perspective Newsletter for December; 2014 Dec [cited 2015 Oct 25]. Available from: http://www.alz.co.uk/global-perspective-news letter-december-2014

15. Gorry C. Primary Care Forward: Raising the Profile of Cuba's Nursing Profession. MEDICC Rev. 2013 Apr;15(2):5-9.

16. Ministry of Public Health (CU). La estrategia cubana para enfrentar la enfermedad de Alzheimer y los síndromes demenciales [Internet]. Havana: Ministry of Public Health (CU); 2013 [cited 2016 Mar 20]. 53 p. Available from: http://files.sld.cu/alzheimer/ files/2015/06/estrategia-9-dic.pdf. Spanish.

17. Varela-Ruiz M, Díaz-Bravo L, GarcíaDurán R. Descripción y el uso del Método DELPHI en investigaciones del área de la salud. Invest Educ Méd [Internet]. 2012 Apr-Jun [cited 2015 Jun 21];1(2):90-5. Available from: http://www.scielo.org.mx/ scielo.php?script=sci_arttext\&pid=S2007 $-50572012000200007 \& \operatorname{lng}=e s$. Spanish.

18. Ministry of Public Health (CU). Programa de atención integral al adulto mayor. Sub-programa de atención comunitaria. Havana: Ministry of Public Health (CU). Spanish.

19. Forbes D, Forbes SC, Blake CM, Thiessen EJ, Forbes S. Exercise programs for people with dementia. Cochrane Database Syst Rev [Internet]. 2015 Apr 15 [cited 2016 Feb 8];(4):CD006489. Available from: http://www.ncbi.nlm.nih.gov/ pubmed/25874613

20. Barnes DE, Yaffe K. The projected effect of risk factor reduction on Alzheimer's disease prevalence. Lancet Neurol [Internet]. 2011 Sep [cited 2013 Jan 21];10:819-28. Available from: http://www.ncbi.nlm.nih.gov/pmc/articles/ PMC3647614/
21. Bickel H, Ander KH, Brönner M, Etgen T, Gnahn $\mathrm{H}$, Gotzler O, et al. Reduction of long-term care dependence after an 8-year primary care prevention program for stroke and dementia: The INVADE Trial. J Am Heart Assoc [Internet]. 2012 Aug 24 [cited 2014 May 7];1(4). Available from: http://jaha.ahajournals.org/content/1/4/ e000786

22. de Bruijn RFAG, Bos MJ, Portegies MLP, Hofman A, Franco $\mathrm{OH}$, Koudstaal PJ, et al. The potential for prevention of dementia across two decades: the prospective, population-based Rotterdam Study. BMC Med [Internet]. 2015 Jul 21 [cited 2016 Jan 7];13(1):132. Available from: http://www .biomedcentral.com/1741-7015/13/132/abstract

23. Satizabal CL, Beiser AS, Chouraki V, Chêne G, Dufouil C, Seshadri S. Incidence of dementia over three decades in the Framingham Heart Study. N Engl J Med [Internet]. 2016 Feb 11 [cited 2016 Jul 23];374(6):523-32. Available from: http://www.nejm.org/doi/full/10.1056/NEJ Moa1504327

\section{THE AUTHORS}

Rodolfo I. Bosch-Bayard (Corresponding author: rodolfobosch@infomed.sld.cu), internist with a master's degree in public health and aging. Associate professor, Alzheimer Studies Department, Finlay Albarrán Medical Faculty, Medical University of Havana (UCMH), Cuba.

Juan de J. Llibre-Rodríguez, internist with a doctorate in health sciences and an advanced doctorate. Full professor and senior researcher, head of Alzheimer Studies Department, UCMH, Havana, Cuba.

Alberto Fernández-Seco, family physician with a master's degree in social gerontology. Head, Older Adult, Social Assistance and Mental Health Department, Ministry of Public Health (MINSAP), Havana, Cuba.
Carmen Borrego-Calzadilla, psychiatrist with a master's degree in emergency medicine in primary care. Head, Mental Health Section, Older Adult, Social Assistance and Mental Health Department, MINSAP, Havana, Cuba.

Mayra R. Carrasco-García, physician with dual specialties in geriatrics and internal medicine and a master's degree in healthy aging. Associate and consulting professor and head, Geriatrics Service, Salvador Allende ClinicalSurgical Teaching Hospital, Havana, Cuba.

Tania Zallas-Llerena, information management specialist. Assistant professor, Alzheimer Studies Department, Finlay Albarrán Faculty, UCMH, Havana Cuba.

Carmen Moreno-Carbonell, physician with dual specialties in epidemiology and occupational health and a master's degree in healthy aging. Full and consulting professor, Alzheimer Studies Department, Finlay Albarrán Faculty, UCMH, Havana, Cuba.

Ana G. Reymond-Vasconcelos, family physician with a master's degree in public health Deputy director for education, Playa Teaching Polyclinic, Havana, Cuba.

Submitted: March 11, 2016

Approved for publication: September 5, 2016 Disclosures: None 